possibilities : either (1) the nebulæ are normal in composition and the earth has lost neon, nitrogen, and argon, or (2) the earth is normal, and the nebulæ are low in oxygen and argon content relative to neon.

As regards (1), Russell and Menzel ${ }^{5}$ have shown that light gases such as neon and nitrogen would completely disappear from the earth, if and when it were hot enough, long before heavier gases like argon even began to escape. Possibility (2) might be caused by the oxygen and argon at the low black body temperature in the nebula $\left(15^{\circ}\right.$ to $20^{\circ} \mathrm{K}$.) freezing out on dust particles (the presence of which in the nebulæ has already been suggested on other grounds ${ }^{2}$ ). The freezing points are: oxygen, $55^{\circ} \mathrm{K}$.; argon, $85^{\circ} \mathrm{K}$. ; nitrogen, $62^{\circ} \mathrm{K}$. ; neon, $20^{\circ} \mathrm{K}$. Unless almost all the oxygen were in combination in the dust particles, however, this still leaves unexplained the high content of argon which, freezing at a higher temperature than oxygen, should be more completely solidified.

We conclude that there is as yet no completely satisfactory explanation of these abundances.

University Observatory, T. L. PAGE. Oxford.

Aug. 25.

1 I. S. Bowen, Rev. Mod. Phys., 8, 69 (1936).

T. L. Page, Mon. Not. Roy. Ast. Soc., 98, 622 (1936).

s cf. Eddington, "Internal Constitution of the Stars", p. 383 (Cambridge, 1926).

- Lick. Obs. Bull., 15, 97 (1930).

' Russell and Menzel, Proc. Nat. Acad. Sci., 19, 997 (1933).

\section{Radioactive Isotopes of Bromine}

FERMI and his collaborators ${ }^{1}$ detected two unstable isotopes of bromine characterized by half-periods of eighteen minutes and $4 \cdot 2$ hours. The nuclear trans. formations are probably expressed by the equations :

(1) ${ }_{35}^{79} \mathrm{Br}+{ }_{0}^{1} n \rightarrow{ }_{35}^{80} \mathrm{Br} \rightarrow{ }_{36}^{80} \mathrm{Kr}+e^{-}$;

(2) ${ }_{35}^{81} \mathrm{Br}+{ }_{6}^{1} n \rightarrow{ }_{35}^{82} \mathrm{Br} \rightarrow{ }_{38}^{82} \mathrm{Kr}+e^{-}$.

The isotopes 80,82 , of krypton are normal constituents of the element.

We noticed that when pure liquid bromine was exposed to neutrons for a week and then transferred to $a$ thin-walled cylindrical glass cell encompassing a Geiger-Müller counter, the instrument registered twenty impulses per minute after a lapse of thirty hours. Previously we had observed the phenomenon in silver bromide precipitated from an irradiated aqueous solution of ammonium bromide. The time of half-decay is provisionally estimated to be twentyfour hours.

As a result of many experiments we conclude that the following reactions occur very infrequently, if at all :

(3) ${ }_{35}^{79,81} \mathrm{Br}+{ }_{0}^{1} n \rightarrow{ }_{34}^{79,81} \mathrm{Se}+{ }_{1}^{1} \mathrm{H}$;

(4) ${ }_{35}^{79,81} \mathrm{Br}+{ }_{0}^{1} n \rightarrow{ }_{33}^{76,78} \mathrm{As}+{ }_{2}^{4} \mathrm{He}$.

Selenium, and arsenious sulphide, precipitated from irradiated solutions of ammonium bromide exhibit no long-period activity. This excludes, in particular,
${ }_{33}^{76} \mathrm{As}\left(t_{1 / 2}=26\right.$ hours $)$ as a possible source of the 'twenty. four hours' activity. The likelihood that it is due to another radioactive isotope of bromine or to an excited bromine nucleus is strengthened by the fact that we have not succeeded in separating the 'twenty-four hour' period from the other two; that is, all three activities in nearly the same relative proportions (small variations would be anticipated) have been observed irrespective of the form in which bromine is presented to the counter. Up to the present, bromine, ammonium bromide, silver bromide, lead bromide, and ethylene dibromide have been examined. To an irradiated solution of ammonium bromide, arsenic and selenium compounds were added, and pure samples of the three salts obtained from the mixture. Ethylene dibromide was prepared from radioactive bromine.

When, as in this case, the number of recognizable half-periods exceeds the number of isotopes in the natural element, several hypotheses can be suggested to explain their origin. Moreover, the half-periods are often difficult to determine precisely, and may sometimes be compounded of two or more. If there are, in fact, only three periods characteristic of bromine, the simplest explanation appears to be that a neutron is either absorbed, equations (1) and (2), or causes the expulsion of another neutron, thus :

(5) ${ }_{35}^{79} \mathrm{Br}+{ }_{0}^{1} n \rightarrow{ }_{35}^{78} \mathrm{Br}+2{ }_{0}^{1} n$;

(6) ${ }_{35}^{81} \mathrm{Br}+{ }_{0}^{1} n \rightarrow{ }_{35}^{80} \mathrm{Br}+2{ }_{0}^{1} n$.

Fermi $^{1}$ discussed this type of collision, but did not observe it. Bromine atoms of mass 80 are produced by reactions (1) and (6), and until a fourth half-period can be shown to exist must be presumed identical. The isotope ${ }_{35}^{78} \mathrm{Br}$ may emit a positron or an electron, becoming ${ }_{34}^{78} \mathrm{Se}$ or ${ }_{36}^{28} \mathrm{Kr}$. These are stable.

In our experiments the substances were exposed to fast and slow neutrons (and $\gamma$-radiation) produced by a mixture of beryllium dust and radium bromide. Fast neutrons are probably required to bring about reactions (5) and (6). The effect of varying the relative concentrations of slow and fast neutrons will shortly be investigated. The main results are summarized in the accompanying table :

\begin{tabular}{|c|c|c|}
\hline Half-period & $\begin{array}{c}\text { Relative initial } \\
\text { activity }\end{array}$ & $\begin{array}{c}\text { Relative total } \\
\text { activity }\end{array}$ \\
\hline 18 min. & 8 & 1 \\
$4 \cdot 2$ hours & $3 \cdot 5$ & 6 \\
24 hours (?) & 1 & 10 \\
\hline
\end{tabular}

Figures in the third column are proportional to the total number of impulses given to the Geiger-Muller counter during the whole period of decay. They are of interest in connexion with the hypothesis suggested above, wherein isotope 82 is produced by absorption of a neutron, 78 by disintegration, and 80 by both processes, but an attempt to assign half-periods to particular isotopes would be premature at this stage.

C. H. Johnson.

F. T. Hamblin.

Department of Physical Chemistry, University, Bristol. Aug. 19.

Proc. Roy. Soc., A, 146, 483 (1934); A, 149, 522 (1935). 